\title{
Rainfall Trend Analysis in the City of Villahermosa,
}

\section{Mexico}

\author{
Ana Victoria Gómez Alejandro and Heliodoro Daniel Cruz Suárez \\ División Académica de Ciencias Básicas, Universidad Juárez Autónoma de Tabasco, Cunduacán 86690, México
}

\begin{abstract}
In this paper, a study by means of linear regression of rainfall in Villahermosa is proposed, within the study area 5 meteorological stations distributed in the city were analyzed because it is one of the most populated areas of the state, once estimated the data, the non-parametric Mann-Kendall test was used to determine increasing or decreasing linear trends in precipitation. To determine the usefulness of statistical inference, the linear correlation coefficient $(r)$ was calculated, which was 0.86 on average. Statistical efficiency $(E)$ was also calculated, which in all the cases analyzed suggests the viability of statistical inference. As a result of this analysis, a complete rainfall database is presented and evaluated for increasing or decreasing trends for the 1980-2010 period.
\end{abstract}

Key words: Rainfall, linear regression, Mann Kendall, trend analysis.

\section{Nomenclature}

$\begin{array}{ll}X: & \text { independent variable } \\ Y: & \text { dependent variable } \\ R: & \text { correlation coefficient } \\ R^{2}: & \text { coefficient of determination } \\ S: & \text { Mann Kendall statistic } \\ m: & \text { Sen's slope } \\ H_{0}: & \text { null hypothesis } \\ H_{l}: & \text { alternate hypothesis } \\ \bar{x}: & \text { average of } \mathrm{x}\end{array}$

\section{Greek Letters}

$\begin{array}{ll}\beta_{0}: & \text { intercept } \\ \beta_{1}: & \text { slope } \\ \varepsilon: & \text { random error } \\ \Sigma: & \text { summation }\end{array}$

\section{Introduction}

In the state of Tabasco and the rest of the country, the National Meteorological Service (SMN) and the National Water Commission (CONAGUA) maintain climatic records. Due to the instrumentation used in the stations there are data that were not registered, being the only institutions that provide such free access data,

Corresponding author: Ana Victoria Gómez Alejandro, student, research fields: atmosfericsciences, climatology. for any analysis it is necessary to complete the missing information.

In Mexico the distribution of precipitation varies greatly in space and time, is heterogeneous throughout the year, intimately linked to the orography of the country and is affected by its proximity to the Pacific Ocean and the Gulf of Mexico [1]. Today the science of precipitation is at the crossroads of different scientific disciplines including hydrology, numerical modeling, climate change, remote sensing, climate prediction among others [2]. Temperature and precipitation are fundamental components of climate and changes in their patterns can affect human health, ecosystems, plants and animals [3]. The trends in rainfall have a great impact on the hydrological cycle, affecting the quantity and state of water resources, their analysis also helps to see the result of variability in precipitation when droughts and floods occur [4]. Studying regional climate variability is essential for planning the management of a country's natural resources [5].

There are several methods to complete the missing values in a pluviometric series. Ref. [6] proposed several statistical methods for the filling of missing values, including linear regression, the ratio method and the normal ratio. The linear regression method is 
one of the most used when it is necessary to estimate missing temperature and precipitation data, its frequent use is due to the simplicity of the method since it gives clear and precise results $[7,8]$. Linear regression is also one of the most common tests to detect trends, which assumes a normal distribution of data; on the other hand, there is the non-parametric Mann-Kendall test that can analyze the information regardless of the distribution and lost data, which is why it has been widely used in environmental sciences [9].

In this paper, linear regression is used to estimate monthly precipitation data based on the goodness of fit of the model and thus verify with statistical efficiency if the model made an adequate estimation of the data and determine if there are increasing or decreasing linear trends in precipitation, on an annual and monthly scale during the period 1980-2010, using the non-parametric Mann-Kendall test and the slope method of Sen to quantify the trend [10]. As a result a complete rainfall database is presented and evaluated for increasing or decreasing trends for the 1980-2010 period.

The paper is organized as follows: in the second section materials and methods are presented, while in the third section experiments results are obtained. Finally, conclusions and references are given.

\section{Statistical Methods}

The state of Tabasco is in the tropical zone of the southeast of Mexico [Fig. 1], between $17^{\circ}-18^{\circ}$ north latitude and $91^{\circ}-94^{\circ}$ west longitude. The $95 \%$ of its territory has a flat relief and slight depressions that correspond to flood areas and swamps. Tabasco is part of the Physiographic Province called Coastal Plain of the South Gulf, in which the Humid Warm climate predominates, with average rainfall per year of 1,526.4 $\mathrm{mm}$ the minimum and 2,600.9 $\mathrm{mm}$ the maximum [11].

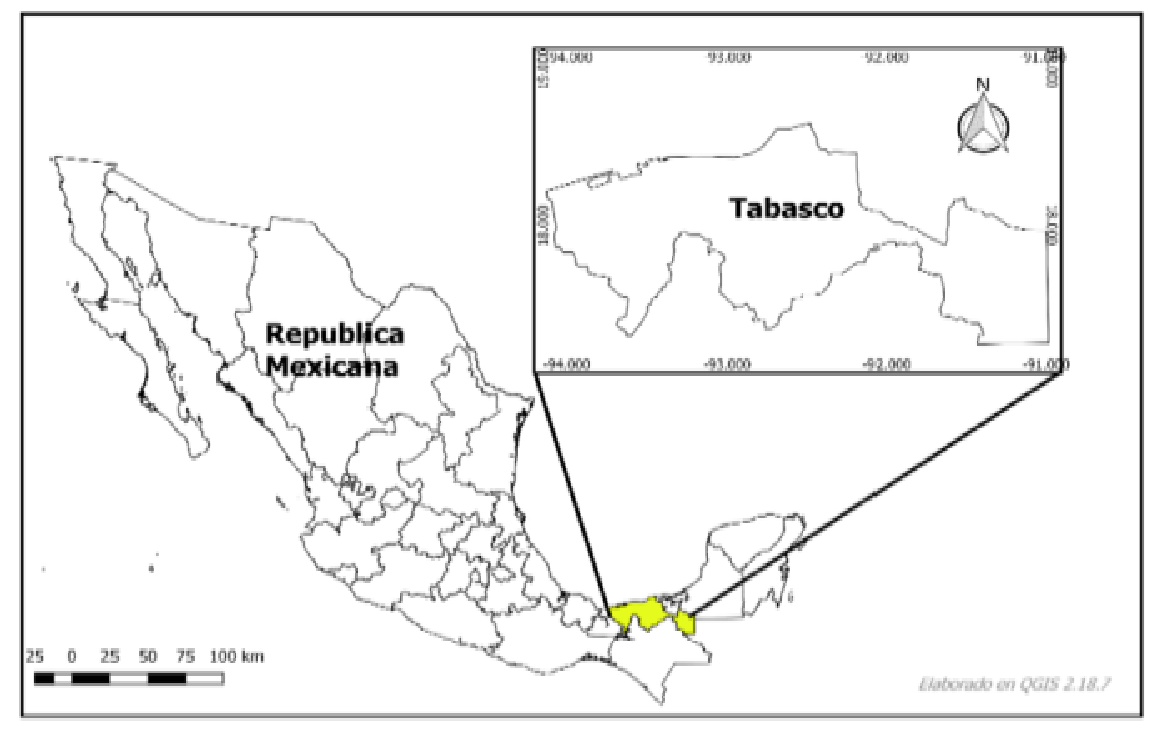

Fig. 1 Location of the study area.

Table 1 Data of stations used in the study.

\begin{tabular}{lllll}
\hline ID & Station (Centro, Tabasco) & Longitude & Latitude & $\begin{array}{l}\text { Altitude } \\
\text { (MSNM) }\end{array}$ \\
\hline 27055 & VILLAHERMOSA (SMN) & -92.928 & 17.997 & 6 \\
27054 & VILLAHERMOSA (DGE) & -92.928 & 17.997 & 24 \\
27065 & DOS MONTES (DM) & -92.767 & 17.978 & 14 \\
27096 & PORVENIR (PRVN) & -92.881 & 18.008 & 5 \\
27014 & ESCUELA DE INGENIERIA (EI) & -92.933 & 18.017 & 7 \\
\hline
\end{tabular}




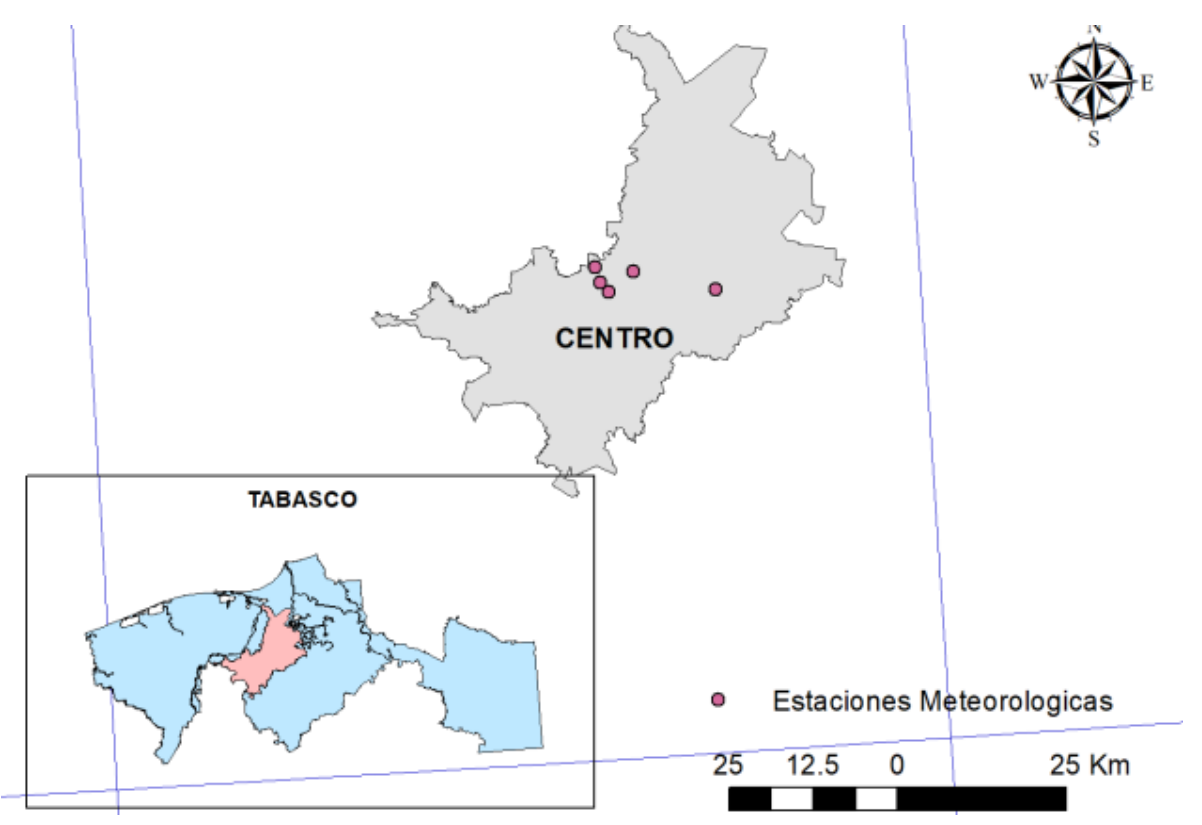

Fig. 2 Location of stations.

The information used in this work is part of the data record monitored by the existing stations in the CLICOM database. Fig. 2 and Table 1 show the information of the stations used in the study.

\subsection{Linear Regression by Least Squares}

According to Ref. [12] regression analysis is a statistical technique for the modeling and investigation of the relationship of two or more variables. The case of simple linear regression considers only a regressor or predictor $x$, and a dependent variable or answer $Y$. Suppose that the true relation between $Y$ and $x$ is a straight line, and that the observation $Y$ in each level $x$ is a random variable.

$$
\mathrm{Y}=\beta_{0}+\beta_{1} x+\epsilon
$$

where the intercept $\beta_{0}$ and the slope $\beta_{1}$ are the unknown coefficients of the regression, $\varepsilon$ is a random error with zero mean and variance $\sigma^{2}$.

The estimates of $\beta_{0}$ and $\beta_{1}$ should result in a line that fits the data as best as possible. Estimating the parameters $\beta_{0}$ and $\beta_{1}$ of the equation so that the sum of the squares of the vertical deviations is minimized is known as the least squares method. The least squares estimates, of the ordinate to the origin and the slope, of the simple linear regression model are:

$$
\begin{gathered}
\hat{\beta}_{0}=\hat{y}-\hat{\beta}_{1} \bar{x} \\
\widehat{\boldsymbol{\beta}}_{\mathbf{0}}=\frac{\sum_{i=1}^{n} \boldsymbol{y}_{i} \boldsymbol{x}_{\boldsymbol{i}}-\frac{\left(\sum_{i=1}^{n} y_{i}\right)\left(\sum_{i=1}^{n} x_{i}\right)}{n}}{\sum_{i=1}^{n} \boldsymbol{x}_{\boldsymbol{i}^{2}}-\frac{\left(\sum_{i=1}^{n} x_{i}\right)^{2}}{n}}
\end{gathered}
$$

where $\bar{y}=(1 / n) \sum_{i=1}^{n} y_{i}$ and $\bar{x}=(1 / n) \sum_{i=1}^{n} x_{i}$.

\subsection{Coefficient of Determination $R^{2}$}

According to Ref. [13], the coefficient of determination is the most used factor to verify the goodness of fit of the model, since it measures the percentage of the total variation in the dependent variable that is explained by the estimated model, the value is contained between 0 and 1 . The closer to 1 , the greater the adjustment of the proposed model, on the contrary, when the value of $R^{2}$ is close to 0 , then the constructed model shows in a low percentage the variability of the dependent variable $Y$. The coefficient of determination has the following structure:

$$
R^{2}=\frac{\sum\left(\hat{Y}_{i}-\bar{Y}\right)^{2}}{\sum\left(Y_{i}-\bar{Y}\right)^{2}}
$$

\subsection{Statistical Efficiency}

The statistical efficiency $(E)$ helps to determine if it improves the average value of the record $y$ and, therefore if it is convenient to make the inference. If the 
value of $(E)$ is greater than one, it will not improve the record of the $y_{i}$, on the contrary, if $(E)$ is less than the unity, it is convenient to make the inference of the missing values from the xi. The statistical efficiency is calculated in the following way according to Ref. [14]:

$$
E=1-r^{2}\left(\frac{n-m}{n}\right)+\frac{n-m}{n(m-3)}\left(1-r^{2}\right)
$$

where $m=$ total data number of $y ; n=$ total data number of $x ; r=$ correlation coefficient.

\subsection{Student's t-Test}

If you want to test the hypothesis that the slope is equal to a constant, for example $\mathrm{B}_{1,0}$. The appropriate hypotheses are:

$$
\begin{aligned}
\mathrm{H}_{0}: \mathrm{B}_{1} & =\mathrm{B}_{1,0} \\
\mathrm{H}_{1}: \mathrm{B}_{1} & \neq \mathrm{B}_{1,0}
\end{aligned}
$$

The statistic $T$ is calculated as follows:

$$
T_{0}=\frac{\hat{B}_{1}-B_{1,0}}{\sqrt{\widehat{\sigma}^{2} / S_{x x}}}
$$

A very special case is $\mathrm{H}_{0}: \mathrm{B}_{1}=0$ and $\mathrm{H}_{1}: \mathrm{B}_{1} \neq 0$. These hypotheses are related to the significance of the regression. The failure to reject $\mathrm{H}_{0}: \mathrm{B}_{1}=0$ is equivalent to concluding that there is no linear relationship between $\mathrm{x}$ and $Y$ [12].

\subsection{Mann-Kendall Test}

In this test each data value in the time series is compared to all subsequent values. Initially, the Mann-Kendall $(S)$ statistics are zero, and if a data value in subsequent periods of time is greater than a data value in previous time periods, $S$ is increased by 1 and vice versa. The net result of all these increases and decreases gives the final value of $S$. The Mann-Kendall statistics $(S)$ are given as:

$$
S=\sum_{i=1}^{n-1} \sum_{j=i+1}^{n} \operatorname{sign}\left(x_{j}-x_{i}\right)
$$

where $\operatorname{sign}\left(x_{j}-x_{k}\right)=1$.

If $\left(x_{j}-x_{k}\right)>0 ; 0$, if $\left(x_{j}-x_{k}\right)=0 ;-1$ if $\left(x_{j}-x_{k}\right)<0$.

A positive value of $S$ indicates a rising trend and a negative value indicates a decreasing trend. However, it is necessary to perform the statistical analysis for the importance of the trend. The test procedure using the normal approach test is described in Ref. [15]. The variance $(S)$ is calculated by the following equation:

$$
\operatorname{Var}(S)=\frac{1}{18}\left[n(n-1)(2 n+5)-\sum_{p=1}^{g} t_{p}\left(t_{p}-\right.\right.
$$

1) $(2 \mathrm{tp}+5)(10)$

where $n$ is the number of data, $g$ the number of grouped data and $t_{p}$ the number of data in the group $p$.

\subsection{Estimator of Sen's Slope}

The Sen's slope is estimated as the average of all the slopes between each pair of points in the database [16], each slope is estimated using the following equation:

$$
m_{i j}=\frac{\left(Y_{j}-Y_{i}\right)}{(j-i)}
$$

where $i=1$ to $n-1, j=2$ to $n, Y_{j}$ and $Y_{i}$ are data values at time $j$ and $i(j>i)$, respectively. If there are $n$ values of $Y_{j}$ in the time series, there will be $N=n(n-1) / 2$ estimated slopes. The slope of Sen is:

$$
\begin{aligned}
& m=m_{\left[\frac{N+1}{2}\right]}, \text { if } n \text { is odd } \\
& m=\frac{1}{2}\left(m_{\left[\frac{N}{2}\right]}+m_{\left[\frac{N+2}{2}\right]}\right) \text {, if } n \text { is pair }
\end{aligned}
$$

A positive Sen slope indicates an increasing trend while a negative indicates a decreasing trend.

\section{Results}

For the stations of the city of Villahermosa, from the climatological rainfall variable, a linear regression analysis was carried out between nearby stations in order to calculate the correlation and determination coefficients, as well as the statistical efficiency and the $p$-value for the intercept and the slope of the lines generated for the monthly models, these results are presented below.

Table 2 shows the results of the statistical parameters that suggest that it is feasible to make the statistical inference of the missing data by linear regression analysis. Fig. 3 shows the scatter diagrams of the precipitation data reported by a pair of stations and their corresponding regression lines, in all cases the linear 
Table 2 Calculated data of inference and statistical efficiency.

\begin{tabular}{lllllll}
\hline Months & $\mathrm{X}_{\mathrm{i}}$ & $\mathrm{Y}_{\mathrm{i}}$ & $\mathrm{R}$ & $\mathrm{R}^{2}$ & $p$-value intercept/slope & Statistical efficiency \\
\hline January & DGE & PRVN & 0.9952 & 0.9905 & $0.0011 / 0.0000$ & 0.54 \\
February & DGE & PRVN & 0.9911 & 0.9823 & $0.0000 / 0.0000$ & 0.54 \\
March & DGE & PRVN & 0.9739 & 0.9484 & $0.0000 / 0.0000$ & 0.56 \\
April & DGE & PRVN & 0.9484 & 0.8995 & $0.0014 / 0.0000$ & 0.58 \\
May & DGE & PRVN & 0.9850 & 0.9703 & $0.0002 / 0.0000$ & 0.55 \\
June & DGE & PRVN & 0.9981 & 0.9963 & $0.0000 / 0.0000$ & 0.54 \\
July & DGE & PRVN & 0.9910 & 0.9821 & $0.0000 / 0.0000$ & 0.54 \\
August & DGE & PRVN & 0.9891 & 0.9783 & $0.0000 / 0.0000$ & 0.54 \\
September & DGE & PRVN & 0.9961 & 0.9923 & $0.0000 / 0.0000$ & 0.54 \\
October & DGE & PRVN & 0.9981 & 0.9963 & $0.0000 / 0.0000$ & 0.54 \\
November & DGE & PRVN & 0.9922 & 0.9845 & $0.0001 / 0.0000$ & 0.54 \\
December & DGE & PRVN & 0.9899 & 0.9800 & $0.0001 / 0.0000$ & 0.54 \\
\hline
\end{tabular}
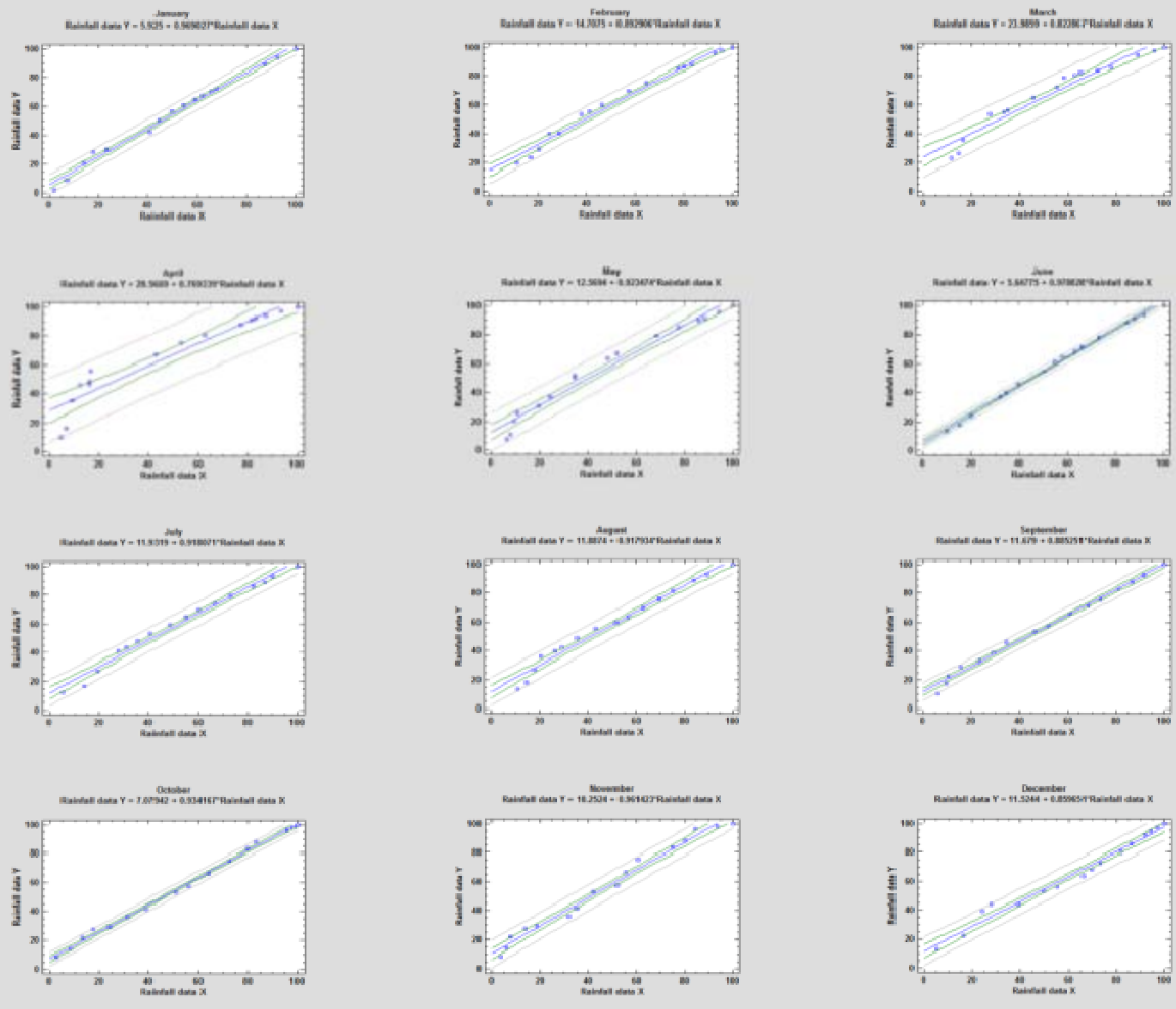

Fig. 3 Scatter diagrams and regression lines of the pair of DGE-Porvenir stations, with which the missing data was filled.

adjustment has values of $\mathrm{m}>0$, this is justified thanks to the $p$-value obtained for the slope, the above shows that there is a strong positive linear correlation between the variables. An average coefficient of determination of 0.97 was obtained for the generated models and an average statistical efficiency is 0.54 .

Table 3 shows the data of the monthly rainfall observed in the city of Villahermosa during 1980-2010, monitored by the Porvenir station, it also shows the estimations that were made. 
It is important to mention that only one table is shown with the inference and statistical efficiency since the obtained results had a similar trend in the other analyzed stations, the same applies for the linear regression models generated monthly for each station.

Table 4 shows the results of applying the Mann-Kendall test and the Sen slope estimator, for the 12 months of the study period, to an average of the 5 stations. Being the null hypothesis $\mathrm{H}_{0}=0$ (there is no trend in the series) and alternative $\mathrm{H}_{1} \neq 0$ (there is a trend), with level of significance $(\alpha=0.05)$ the obtained $p$ values show that no trends are detected in the analyzed period. The statistic $(\mathrm{S})$ of $\mathrm{MK}$ is negative for all months except April (3), May (15) and August (29), in turn the slope of Sen obtained is 0.007 for the first, 0.348 for the second and 0.510 for the third indicating a growing trend. Despite the insufficient statistical evidence of a significant trend, the slope of Sen is negative for all months except those mentioned above, which indicates a decreasing trend in precipitation over time. Table 5 shows the results of the annual total for the same test and according to the $p$-value obtained no trend is presented, the value of the MK test is -53.000 which points to a decrease in precipitation along with the Sen slope (-0.702).

Table 3 The complete monthly precipitation record of the Porvenir station is presented, for the period 1980-2010.

\begin{tabular}{|c|c|c|c|c|c|c|c|c|c|c|c|c|}
\hline Año & Enero & Febrero & Marzo & Abril & Mayo & Junio & Julio & Agosto & Septiembre & Octubre & Noviembre & Diciembre \\
\hline 1980 & 79.3 & 137.1 & 57.3 & 88.6 & 41.5 & 169.6 & 133.3 & 109.0 & 363.5 & 888.0 & 319.9 & 101.1 \\
\hline 1981 & 31.0 & 307.2 & 169.2 & 83.3 & 82.5 & 534.7 & 418.6 & 585.2 & 502.2 & 439.8 & 153.2 & 299.1 \\
\hline 1982 & 125.1 & 153.1 & 57.6 & 56.3 & 189.7 & 228.7 & 132.6 & 130.7 & 474.2 & 241.5 & 184.8 & 174.5 \\
\hline 1983 & 120.5 & 70.8 & 28.9 & 54.2 & 33.9 & 164.7 & 155.2 & 194.8 & 374.2 & 298.4 & 149.9 & 206.3 \\
\hline 1984 & 176.8 & 39.4 & 37.3 & 28.6 & 403.3 & 205.6 & 183.0 & 328.3 & 377.3 & 137.5 & 212.3 & 95.8 \\
\hline 1985 & 190.9 & 94.2 & 67.8 & 158.8 & 102.2 & 237.0 & 351.2 & 392.7 & 234.3 & 401.0 & 79.7 & 397.7 \\
\hline 1986 & 136.5 & 68.8 & 58.6 & 28.6 & 231.3 & 122.6 & 85.0 & 128.5 & 103.0 & 102.5 & 130.3 & 51.3 \\
\hline 1987 & 132.1 & 169.1 & 133.1 & 89.2 & 58.6 & 509.6 & 480.9 & 411.0 & 328.6 & 320.3 & 204.7 & 105.2 \\
\hline 1988 & 184.3 & 136.5 & 75.9 & 58.3 & 21.2 & 351.5 & 262.8 & 576.7 & 350.6 & 606.1 & 297.3 & 92.7 \\
\hline 1989 & 32.8 & 11.2 & 8.6 & 5.5 & 54.1 & 120.2 & 90.2 & 148.4 & 196.1 & 100.6 & 17.9 & 8.2 \\
\hline 1990 & 106.2 & 183.2 & 91.2 & 41.6 & 110.7 & 173.4 & 131.8 & 207.7 & 214.8 & 245.7 & 117.3 & 290.8 \\
\hline 1991 & 207.5 & 206.2 & 9.9 & 19.6 & 65.6 & 233.8 & 129.2 & 123.1 & 266.2 & 362.1 & 227.8 & 190.1 \\
\hline 1992 & 274.7 & 125.2 & 88.6 & 59.8 & 105.5 & 334.8 & 55.3 & 294.3 & 313.9 & 275.8 & 319.5 & 67.1 \\
\hline 1993 & 137.4 & 28.8 & 63.3 & 58.5 & 146.4 & 350.5 & 182.7 & 276.1 & 376.9 & 270.2 & 116.5 & 77.7 \\
\hline 1994 & 132.3 & 75.7 & 49.7 & 97.0 & 92.0 & 85.3 & 98.9 & 275.3 & 241.3 & 134.1 & 95.2 & 148.0 \\
\hline 1995 & 100.6 & 73.5 & 56.6 & 95.8 & 12.5 & 247.9 & 220.7 & 286.9 & 366.6 & 602.4 & 136.1 & 177.0 \\
\hline 1996 & 92.2 & 23.6 & 92.9 & 110.0 & 137.0 & 148.2 & 287.3 & 212.5 & 150.5 & 346.9 & 174.8 & 99.5 \\
\hline 1997 & 72.2 & 155.2 & 48.7 & 65.3 & 125.1 & 136.9 & 188.1 & 189.0 & 208.6 & 247.5 & 235.1 & 99.9 \\
\hline 1998 & 13.8 & 27.6 & 25.3 & 33.6 & 12.6 & 116.1 & 466.9 & 124.8 & 146.3 & 141.2 & 87.3 & 68.3 \\
\hline 1999 & 67.0 & 92.0 & 13.9 & 48.5 & 41.0 & 138.6 & 172.4 & 167.4 & 384.8 & 455.3 & 112.8 & 99.3 \\
\hline 2000 & 69.3 & 40.2 & 40.2 & 35.5 & 289.0 & 167.1 & 96.6 & 92.8 & 131.6 & 126.7 & 78.9 & 62.1 \\
\hline 2001 & 47.5 & 159.9 & 11.7 & 57.2 & 130.1 & 118.0 & 147.7 & 284.2 & 268.8 & 480.2 & 132.7 & 179.4 \\
\hline 2002 & 99.3 & 275.1 & 100.5 & 56.4 & 98.8 & 357.8 & 105.4 & 181.2 & 350.4 & 145.0 & 371.8 & 118.4 \\
\hline 2003 & 49.2 & 17.7 & 9.7 & 27.6 & 62.2 & 276.2 & 173.9 & 239.4 & 217.4 & 426.4 & 232.0 & 128.9 \\
\hline 2004 & 149.5 & 93.8 & 91.1 & 98.8 & 215.9 & 134.2 & 150.2 & 210.3 & 293.3 & 218.8 & 109.3 & 103.3 \\
\hline 2005 & 28.6 & 26.8 & 16.7 & 11.0 & 56.7 & 402.8 & 221.9 & 270.9 & 372.0 & 277.0 & 145.1 & 142.5 \\
\hline 2006 & 195.2 & 102.7 & 75.7 & 44.4 & 168.6 & 375.5 & 234.7 & 246.9 & 282.2 & 404.1 & 173.6 & 212.8 \\
\hline 2007 & 285.2 & 122.5 & 63.0 & 17.8 & 12.2 & 90.7 & 115.4 & 316.8 & 258.3 & 433.8 & 193.7 & 55.0 \\
\hline 2008 & 185.9 & 105.7 & 62.0 & 131.6 & 170.1 & 339.5 & 227.8 & 182.1 & 503.4 & 238.9 & 58.7 & 80.7 \\
\hline 2009 & 71.5 & 30.8 & 25.2 & 23.4 & 46.2 & 114.5 & 133.4 & 181.0 & 225.3 & 82.2 & 232.2 & 60.0 \\
\hline 2010 & 108.7 & 36.4 & 16.6 & 24.7 & 46.8 & 233.0 & 230.9 & 302.0 & 354.3 & 103.7 & 144.1 & 68.0 \\
\hline
\end{tabular}


Table 4 Mann-Kendall test on an average of the 5 stations in the 1980-2010 period.

\begin{tabular}{llll}
\hline Series/test & Mann kendall statistic $(\mathrm{S})$ & $p$-value & Sen's slope \\
\hline Enero & -17.000 & 0.788 & -0.336 \\
Febrero & -55.000 & 0.362 & -1.132 \\
Marzo & -47.000 & 0.438 & -0.396 \\
Abril & 3.000 & 0.973 & 0.007 \\
Mayo & 15.000 & 0.814 & 0.348 \\
Junio & -39.000 & 0.522 & -1.127 \\
Julio & -3.000 & 0.973 & -0.068 \\
Agosto & 29.000 & 0.637 & 0.510 \\
Septiembre & -7.000 & 0.920 & -0.218 \\
Octubre & -53.000 & 0.380 & -2.962 \\
Noviembre & -41.000 & 0.500 & -1.090 \\
Diciembre & -105.000 & 0.077 & -1.920 \\
\hline
\end{tabular}

Table 5 Mann-Kendall test of the 5 stations of the annual total 1980-2010.

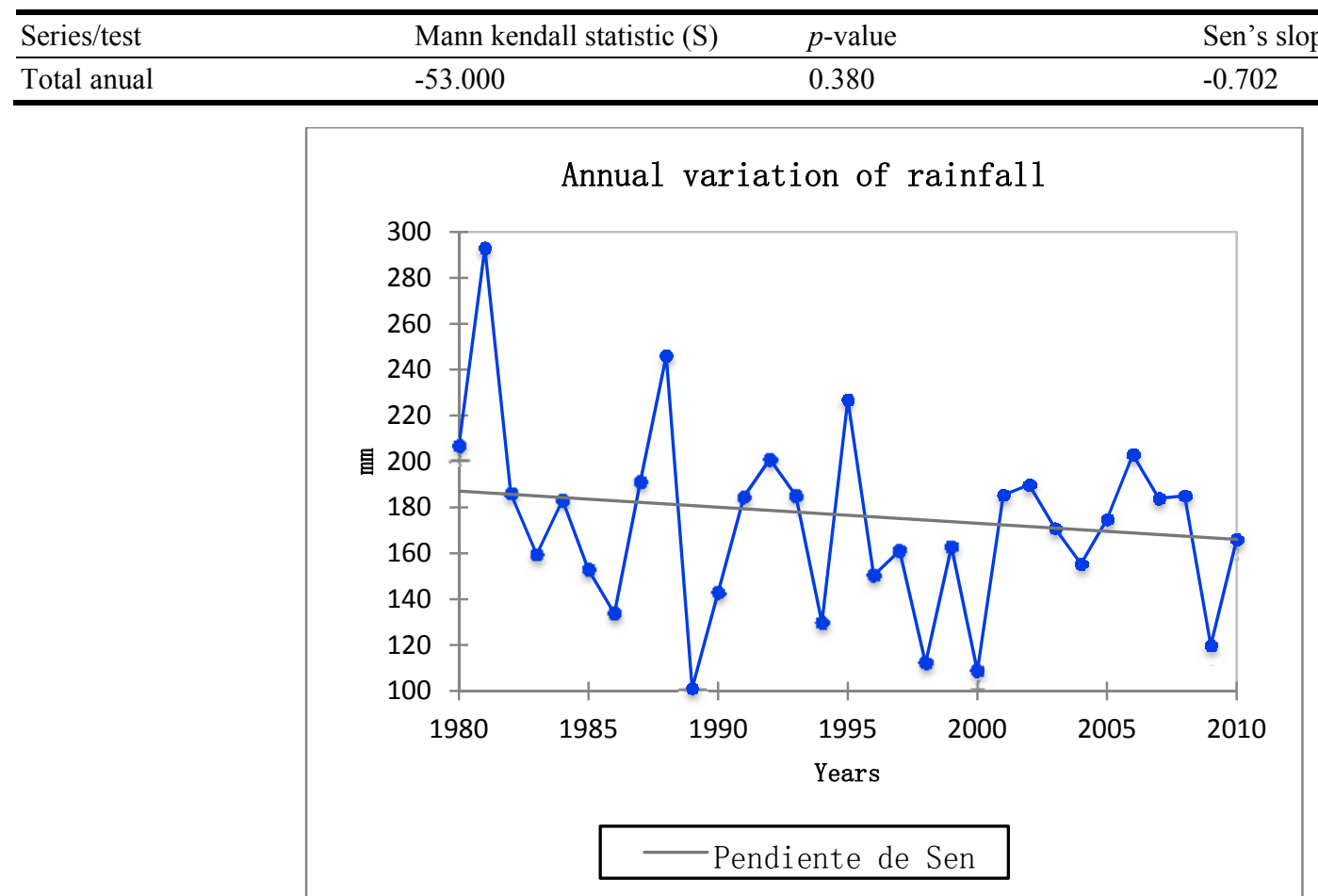

Fig. 4 Annual rainfall of 30 years.

In Fig. 4 it is observed that the year with less precipitation was 1989 with $793.8 \mathrm{~mm}$ and the maximum 1981 with $3,605.9 \mathrm{~mm}$, the average for the 30 years is $2,027.6 \mathrm{~mm}$.

\section{Conclusions}

In our analysis of the $t$-test for the slope, the test statistic depends on the proposed null hypothesis $\left(\mathrm{H}_{0}=\right.$ 0 ) and alternative hypothesis $\left(\mathrm{H}_{1} \neq 0\right)$, as a result a $p$-value was obtained that on average was lower than the level of significance $(\alpha=0.05)$, this allows us to reject $\mathrm{H}_{0}$ and accept $\mathrm{H}_{1}$.

The statistical tests were performed, that is, the average linear correlation coefficient $(\bar{r}=0.9873)$, the average observed value of the coefficient of determination $\left(\mathrm{R}^{2}=0.9751\right)$ and the average statistical efficiency $(\bar{E}=0.54)$ confirm the goodness of the results, this applies in the same way for the remaining 
analyzed stations. Although in the Mann-Kendall test the $p$ values did not allow us to reject the null hypothesis (there is no trend in the series), the values of the MK (S) statistic are negative for all months except April ( 3), May (15) and August (29), together with the values of the slope of Sen (0.007), (0.348) and (0.510) respectively, which indicates an increase in precipitation although nothing significant.

The general trend shows decreasing precipitation in the values of the Sen slope, both for the 12 months of the 30 years and for the annual total of the 1980-2010 period. The above coincides with that described by Ref. [9] who report that the wettest regions of the country have an average rainfall decrease of $1.2 \%$ in total annual precipitation. This study was motivated by the discrepancy in opinion regarding how precipitation has changed in recent years at the study site.

Based on these results this work provides a complete, homogeneous and statistically reliable rainfall database, as well as an analysis of precipitation trends for the 1980-2010 period, due to a slight downward trend future investigations could reveal more aspects that could be of help for the best management of resources in the city of Villahermosa.

\section{References}

[1] García, E. 2003. "Distribución de la precipitación en la República Mexicana." Investigaciones geográficas, Boletín del Instituto de Geografia. UNAM 50: 67-76.

[2] Tapiador, F. J., Turk, F. J., Petersen, W., Hou, A. Y., García-Ortega, E., Machado, L. A., Angelis, C. F., Salio, P., Kidd, C., Huffman, G. J., and De Castro, M. 2012. "Global Precipitation Measurement: Methods, Datasets and Applications." Atmospheric Research 104: 70-97.

[3] Önöz, B., and Bayazit, M. 2003. "The Power of Statistical Tests for Trend Detection." Turkish Journal of
Engineering and Environmental Sciences 27 (4): 247-51.

[4] Ifabiyi, I. P., and Ojoye, S. 2013. "Rainfall Trends in the Sudano-Sahelian Ecological Zone of Nigeria." Earth Science Research 2 (2): 194.

[5] Ayllón, T. 2003. Elementos de meteorología y climatología. México: Editorial Trillas.

[6] Paulhus, J. L., and Kohler, M. A. 1952. "Interpolation of Missing Precipitation Records." Monthly Weather Review 80 (8): 129-33.

[7] Eischeid, J. K., Pasteris, P. A., Diaz, H. F., Plantico, M. S., and Lott, N. J. 2000. "Creating a Serially Complete, National Daily Time Series of Temperature and Precipitation for the Western United States." Journal of Applied Meteorology 39 (9): 1580-91.

[8] Hubbard, K. G., and Siva Kumar, M. V. K. 2001. Automated Weather Stations for Applications in Agriculture and Water Resources Management. Nebraska: High Plains Climate Center and Geneva, Switzerland: WMO.

[9] Méndez González, J., Návar Cháidez, J. D. J., and González Ontiveros, V. 2008. "Análisis de tendencias de precipitación (1920-2004) en México.” Investigaciones geográficas 65: 38-55.

[10] Kumar, N., Panchal, C. C., Chandrawanshi, S. K., and Thanki, J. D. 2017. "Analysis of Rainfall by Using Mann-Kendall Trend, Sen's Slope and Variability at Five Districts of South Gujarat, India.” Mausam 68 (2): 205-22.

[11] INEGI (Instituto Nacional de Estadística y Geografía). 2001. Síntesis de Información Geográfica del Estado de Tabasco. Aguascalientes, México.

[12] Mongomery, D. C., and Runger, G. C. 1996. Probabilidad y Estadística Aplicada a la Ingeniería. México: McGraw-Hill.

[13] Gujarati, D. N., and Porter, D. C. 2010. Econometría. México: McGraw-Hill.

[14] Campos Aranda, D. F. 1998. Procesos del ciclo hidrológico (3rd ed.). San Luis Potosí: McGraw-Hill.

[15] Kendall, M. G. 1975. Rank Correlation Methods. Oxford: Griffin.

[16] Sen, P. K. 1968. "Estimates of the Regression Coefficient Based on Kendall's Tau." Journal of the American Statistical Association 63: 1379-89. 